\title{
Review on Job Embeddedness
}

\author{
Jing Rao ${ }^{1,}$, Shibin $\mathrm{Ma}^{2, \mathrm{~b}}$ \\ ${ }^{1}$ School of Nanjing University of Science and Technology, Nanjing 210000, China \\ ${ }^{2}$ School of Nanjing University of Science and Technology, Nanjing 210000, China

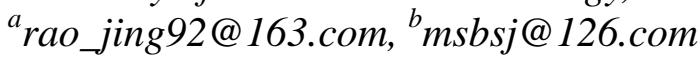

Keywords: job embeddedness; measurement; resignation; retention

\begin{abstract}
Job embeddedness represents the degree of embedding of an individual and a job, proposes more factors that explain employee retention, and can understand the factors that affect employee turnover from a broader perspective. Different types of affective variables such as job embedding and job satisfaction. Job embeddedness includes three dimensions, match, link, and sacrifice. This paper introduces the connotation and dimension of job embeddedness, analyzes the concept difference between related variables, and explains the measurement methods, effects, and influencing factors of job embeddedness. Finally, on the basis of existing theories, the future research will be prospected, and the talent retention strategy based on job embeddedness will be proposed.
\end{abstract}

\section{Introduction}

Today's society is rapidly changing and information is spreading rapidly. People constantly absorb various kinds of information and compare their own environment with the social environment in order to make some major decisions, such as "resignation." The resignation also brings a lot of costs to organizations and individuals, and thus leaving the job becomes a common concern for researchers. A lot of empirical researches have been carried out to analyze the causes and influencing factors of employee turnover. At present, most studies refer to the organizational balance model proposed by March and Simon. This model attributes employee turnover to attitude factors. However, with the deepening of the research, some scholars have questioned the departure model of this kind of traditional attitude variables, and believe that the attitude variable has only a small amount of explanatory power on the separation behavior. Studies by Hom and Griffeth et al. showed that the explanatory power of the attitude variable to the resignation was only $4 \%$ to $5 \%$. Even the resignation intention that was widely considered to be the direct cause of the resignation only explained $12 \%$ of the active resignation. ${ }^{[1-3]}$ Mitchell et al. (2001), a psychology professor at the University of Washington, presented a new concept, Job Embeddedness, which analyzes employee behavior from outside of work and non-subjective factors, and represents employee behavior (For example, employees' automatic turnover and job performance provide a brand-new explanation framework that complements the original theory of organizational behavior. At the same time, due to the objectivity and operability of job embedding, it can provide benefits for management practices. ${ }^{[4]}$. 


\section{Connotation and Dimension of Job Embeddedness}

\subsection{The Meaning of Job Embeddedness}

The concept of job embeddedness provides an effective extension of the scope of research on the antecedent variables in the departure model. The job embeddedness concept is proposed based on three aspects of research. First, a large number of empirical studies on organizational dependence have found that non-working factors have important influence on attachment. Earlier Price and Mueller, Steers, and Mowday and Mobley's departure models included the impact of "non-work" factors; second, some empirical studies have demonstrated that the employee retention factor is organizational level rather than individual attitude level, for example, many companies in the team-cooperation approach, the formation of identity is promoted. Third, the research on the resignation model has found that many satisfied employees have left the organization. Based on different perspectives, they have laid a theoretical foundation for the concept of job embeddedness.

Mitchell et al. used a new perspective to understand employee turnover behaviors from employee retention factors and proposed job embeddedness constructs-a broader set of factors that affect employee retention. ${ }^{[5]}$ The word " embeddedness " derives from the concepts of "Field Theory" and "Embedded Figures" in psychology. "Field Theory" believes that people have a perceptual living space, and all aspects of life are linked to each other through the perceived living space. The "embedded image" was used in psychological tests to find out a simple graphic hidden in a complex image. To determine the independence and dependability of the test site. Mitchell et al. embed the description as "a network in which individuals are bound". The more individuals that are connected, the more likely they are to be included, and therefore it is more difficult to leave the job ${ }^{[5]}$. Yao et al. defined job embeddedness as "comprehensive factors that prevent individuals from leaving their jobs," including factors such as marital status, community involvement, and job tenure ${ }^{[6]}$. At present, the concept of job embeddedness has basically been recognized by researchers and represents the degree of embedding of individuals and work.

\subsection{Job Embeddedness Dimensions}

Mitchell et al. defined job embeddedness as a multidimensional construct describing the different dependencies between individuals and organizations and communities ${ }^{[5]}$. Job embeddedness includes three core variables: linkage, match, and loss. Linkage refers to the degree of association of an employee with another person or other activities; match refers to the degree of match between an employee's work or the community in which he lives and his/her living space; and loss refers to the degree of easy interruption of the link, that is, the price to pay for leaving the organization or the resulting loss. Mitchell et al. further classified work embedding as work-embedded and work-embedded, and considered organizational factors as internal factors, and community factors as external factors. Correspondingly, job embeddedness is reflected in the six dimensions of organizational contact, matching and loss, and community contact, matching, and loss, namely, organizational contact, organizational match, organizational sacrifice, community contact, community match, and community sacrifice.

\section{Job Embeddedness Measurement}

At present, the scale of job embeddedness measurement can be divided into combined measurement and overall measurement according to the measurement principle. Among them, the combined measurement scale is mainly based on 40 entries developed by Mitchell. Based on this, Lee et al. The scale was revised, and the work embedding was divided into two categories of work 
embedding and out-of-work embedding for operation measurement. The original 40 item scale was adjusted to 34 items, and the embedding reliability in the revised scale was 0.84. External embedding reliability is $0.82^{[7]}$. Holtom later revised a 21 item scale.

The overall measurement is based on Cunningham et al.'s job embeddedness 40-item scale, and Cunningham simplified the six dimensions of multiple measurement projects into one project: "I feel comfortable in the organization" (organizational match); The living community feels very comfortable" (community matching); "I maintain a strong connection with the organization" (organizational link); "I maintain a strong bond with the community" (community link); "If I leave the job I will have losses" (organizational sacrifice); "I will lose if I leave the community I live in" (community sacrifice). Each item was measured by Likert's seven-point scale ("strongly disagree" to "strongly agree"). The use of sports college coaches and employees in colleges to conduct a survey of a sample of the scale of the aggregate validity, discriminant validity and predictive validity were tested ${ }^{[8]}$. A seven-item overall measurement scale developed by Crossley [5][10-11]. Diamantopoulos and his collaborators' research found that the 30 projects were measured in accordance with the combination and the overall The principle of scale development is analyzed, and only two of the remaining items are consistent ${ }^{[12]}$.

\section{The Main Research Perspectives of Job Embeddedness}

\subsection{Research on the Pre-Influenced Variables of Job Embeddedness}

Cezar Giosan first conducted a systematic study of the previously embedded variables of work embedding in the empirical study of the variables before job embeddedness. He empirically concludes that age and number of children predict community connections, perceptions of marital opportunities in the community, predictions of community matching and community losses, age-predicted organizational connections, accountability in Big Five personality, job investment, and organizational support. Sensation, perception of choice opportunities, and perception of organizational marital opportunities have a strong predictive power for organizational connections. Big five personality ambitions, superior support, skills transferability, and alternative career opportunities can be predicted Organizational losses ${ }^{[13]}$. Holtom and others analyzed the practical activities embedded in the six dimensions of the work of the top 100 Fortune companies in the United States, laying the foundation for exploring the job embeddedness antecedent model ${ }^{[10]}$. After studying through 259 employees in a large financial company, Allen found that organizing social strategies can increase the degree of embedding of new employees and organizations. At the same time, the organization's collectivism, solidification, and authorization strategies are positively related to the embedded work. ${ }^{[14]}$ Inspired by the Super Career Theory, Thomas linked career stages with work embedding and analyzed the factors affecting job embedding. Thomas believes that the work is embedded in different career development stages and that there are differences in impact factors ${ }^{[15]}$. James P. Burton et al. integrated the work into the departure expansion model and proposed that "shock" is a variable of link expansion model and job embeddedness. The research results believe that work embedding is negatively related to voluntary turnover and has experienced "shock" after Departing individuals, their job embeddedness is higher than those who did not experience "shock" of leaving the individual ${ }^{[16]}$.

\subsection{Empirical Study of Job Embeddedness Results Variables}

Brooks, Croosley, Mallol used work embedding as an antecedent variable to explore the relationship between job embedding and turnover behavior and job performance, and demonstrated that job embeddedness is more effective than traditional resignation prediction variables (such as 
job satisfaction, organizational commitment, job opportunities, etc.) Moreover, job embedding is more powerful than the traditional job departure model in terms of job satisfaction, organizational commitment, and job opportunities. In addition to resignation, job embedding has predictive power for in-role performance and extra-role performance (such as organizational citizenship behavior) ${ }^{[4]}$.

At the same time, the researchers also attempted to explore the different impacts of embedding within work and embedding outside work on turnover and job performance. Lee et al.'s research shows that the embedding of jobs significantly predicts the employee's automatic departure, embedding the job significantly predicts the employee's organizational citizenship behavior and job performance; and Allen's research shows that embedding within the job can predict the resignation and the embedding outside the job cannot predict the resignation. behavior.

\subsection{Research on Job Embeddedness as an Intermediary and Adjusting Variables}

At present, there are few research literatures on job embeddedness as mediation and regulatory variables. Chinese scholars Xiaowei Liang and others first made research in this area in 2005. They incorporated job embeddedness variables into the multi-path mediation model of the relationship between employee organizational performance and turnover intention, and obtained significant validation results, expanded and tested Mitchell et al. proposed the idea of leaving the job model by using the work embeddedness variable as a variable with the same intermediary status as the work attitude variable.

Tomoki Sekiguchi et al. explored the three paths of job embeddedness in leader-member exchange, organizational self-esteem and organizational citizenship behavior, role of regulation between task performance and work embeddedness, leader-member exchange, and self-esteem in organization. model. Erich Bergiel et al. discussed the relationship between human resource practices, job embedding, and automatic turnover, and found that job embedding plays a full regulatory role in the relationship between compensation and auto-departure, and partially regulates executive support and auto-departure, and promotes and automates resignations. The relationship plays a fine-tuning role, but it does not play a regulatory role in the relationship between training and automatic turnover.

\section{Effect of Job Embeddedness}

The job embeddedness is a concept proposed for employee resignation. Its impact on employee turnover intention and turnover behavior is the focus of the researcher's first concern. In the departure model, "shocking" refers to the key events that lead to the employee's idea of leaving the company, either within the organization or outside the organization. In the case of high work embedding, employees and organizations and their surrounding environment have a close attachment relationship. Even if the idea of leaving the company due to "shock", employees can hardly put it into practice. Crossley et al. found that after controlling the impact of other variables, job embedding has a significant negative impact on employee turnover behavior ${ }^{[17]}$. Heavey et al. proposed that work embedding not only has an impact on the individual's separation behavior, but also has an explanatory power for the group leaving ${ }^{[18]}$. With the deepening of research, researchers are no longer satisfied with a general analysis of the relationship between job embedding and turnover. They are trying to find the differences in the impact of job embedding on turnover in different conditions. For example, Jiang et al. found that the negative correlation between organizational embeddedness and turnover intentions is more pronounced in women-dominated organizations and public institutions, and the impact of community embeddedness on turnover intentions is stronger in collectivist cultures ${ }^{[19]}$. Holtom et al.'s follow-up study found that the predictive power of job embeddedness increases with the increase of working years ${ }^{[20]}$. 
On the other hand, researchers also pay attention to the relationship between job embeddedness and turnover in special situations. Kraimer et al. found that the higher degree of embedding work of expatriate employees of multinational corporations during the expatriate period, the stronger the sense of identity of international employees, and the identity identity disorder after returning to the parent company, resulting in leaving the company ${ }^{[21]}$. Smith et al. studied the job embeddedness of military personnel and found that for military personnel, the higher the degree of embeddedness of the organization, the lower the willingness to retire; the higher the embeddedness of the community, the higher the willingness to retire. ${ }^{[22]}$ It can be seen that there is an important boundary condition for job embedding to affect resignation: if organizations and communities are integrated, organizational embedding and community embedding have a consistent impact on resignation; conversely, organizational embedding and community embedding have the opposite impact on resignations.

\section{Job Embeddedness Research Prospects}

Although Crossley proposed the measurement of the overall job embeddedness, it greatly promoted the development of job embeddedness measurement tools, but the job embeddedness measurement still needs further improvement. Currently, the job embeddedness measurement mainly depends on the individual subjective evaluation of its various dimensions. It is bound to be influenced by individual tendencies and cognitive patterns. Differences among individuals will affect individuals' perceptions of the degree of embedding. For example, individuals with negative emotional traits tend to underestimate the opportunities available to the outside world, and they will also affect The degree of embedding with work. At the same time, the concept of job embedding has the characteristics of non-emotionality and multi-dimension. How to overcome the correlation between various dimensions and between each dimension and other organizational behavioral variables, whether the work-embedded connection dimension can be used in social network analysis The replacement of the measurement project is worth further study in the future.

At the same time, how to measure job embeddedness in Chinese context is also one of the issues worth studying. Different cultural backgrounds, individual behaviors, ways of thinking, and values are quite different. Can the projects in the job embeddedness scale reveal the employee's turnover behavior in the Chinese context? How effective is the interpretation? Does the concept of job embedding suit Chinese companies?

\section{References}

[1] Hom P W, Griffeth R W. Employee Turnover, Cincinnati: Southwestern College Publishing, 1995.

[2] Griffeth, R. W., Hom, P. W, Gaertner, S. A Meta-analysis of Antecedents and Correlates of Employee Turnover: Update, Moderator Tests, and Research Implications for the Next Mil- lennium. Journal of Management, 2000, (3): 463-488.

[3] Maertz, C. P. Gampion, M. A. 25 Years of Voluntary Turnover Research: A Review and Critique. International Review of Industrial and Organizational Psychology,1998, (1): 49-81.

[4] Mitchell T. R., Holtom, B. C., Lee T. W., Sablynski C. J., Erez M.. Why People Stay: Using Job Embeddedness to Predict Voluntary Turnover [J]. Academy of Management Journal, 2001, 44(4): 1102- 1121.

[5] Mitchell, T. R. , Holtom, B. C. , Lee, T. Turnover and Retention Research: A Glance at the Past, a Closer Review of the Present, and a Venture into the Future. Academy of Management Journal, 2001.

[6] Yao X, Lee T W, Mitchell T R, et al. Job embeddedness: currentresearch and future directions. Information Age, 2004. $153 \sim 187$

[7] Lee T W, Mitchell T R, Sablynski C J, et al. The effects of job embeddedness on organizational citizenship, job performance, volitional absences, and voluntary turnover. Academy of Management Journal, 2004, 47(5): 711 722

[8] Cunningham G B, Fink J S, Sagas M. Extensions and further examination of the job embeddedness construct. Journal of Sport Management, 2005, 19(3): 319 337

[9] Lee T W, Mitchell T R. The unfolding effects of organizational commitment and anticipated job satisfaction on 
voluntary employee turnover[J]. Motivation \& Emotion, 1991, 15(1):99-121.

[10] Holtom B C, Inderrieden E J. Integrating the Unfolding Model and Job Embeddedness Model to Better Understand Voluntary Turnover[J]. Journal of Managerial Issues, 2006, 18(4):435-452.

[11] Crossley C. D., Bennett R. J., Jex S. M., Burnfield J. L.. Development of a Global Measurement of Job Embeddedness and Integration into a Traditional Model of Turnover[J]. Journal of Applied Psychology, 2007, 92(4): 1031- 1042.

[12] Diamantopoulos A.. The Error Term in Formative Measurement Models: Interpretation and Modeling Implications[J]. Journal of Modelling in Management, 2006, 1(1): 7- 17.

[13] Cerzar Giosan. Antecedent of Job Embededness [D]. 200 (Work Required for the Degree of Doctor of Philosophy) [14] Allen D. G.. Do Organizational Socialization Tactics Influence Newcomer Embeddedness and Turnover? [J]. Journal of Management, 2006, 32(2): 237- 256.

[15] Thomas W. H. Ng, Daniel C. Feldman. Organizational Embeddedness and Occupational Embeddedness Across Career Stages[J]. Joural of Vocational Behavior, 2007, 70(2): 336- 351.

[16] James P. Burton, Brooks C. Holtom, Chris J. Sablynski, Terence R. Mitchell, Thomas W. Lee. The Buffering Effects of Job Embeddedness on Negative Shocks[J]. Journal of Vocational Behavior, 2010, 76(1): 42- 51.

[17] Thau S, Crossley C, Bennett $R$ J, et al. The relationship between trust, attachment, and antisocial work behaviors[J]. Human Relations, 2007, 60(8):1155-1179.

[18] Heavey A L, Holwerda J A, Hausknecht J P. Causes and Consequences of Collective Turnover: A Meta-analytic Review[J]. Journal of Applied Psychology, 2013 (3): 412-453.

[19] Jiang K, Liu D, McKay P F, et al. When and How is Job Embeddedness Predictive of Turnover? A Meta-analytic Investigation[J]. Journal of Applied Psychology, 2012 (5): 1077-1096.

[20] Holtom B C, Tidd S T, Mitchell T R, et al. A Demonstration of the Importance of Temporal Considerations in the Prediction of Newcomer Turnover[J]. Human Relations, 2013 (10): 1337-1352.

[21] Kraimer M L, Shaffer M A, Harrison D A, et al. No Place Like Home? An Identity Strain Perspective on Repatriate Turnover[J]. Academy of Management Journal, 2012(2): 399-420.

[22] Smith D R, Holtom B C, Mitchell T R. Enhancing Precision in the Prediction of Voluntary Turnover and Retirement[J]. Journal of Vocational Behavior, 2011(1): 290 -302. 